\title{
Spatial Patterns and Temporal Trajectories of the Bog Ground Layer Along a Post-Fire Chronosequence
}

\author{
Brian W. Benscoter ${ }^{1,3 *}$ and Dale H. Vitt ${ }^{2}$ \\ ${ }^{1}$ Department of Plant Biology, Michigan State University, 166 Plant Biology, East Lansing, Michigan 48824, USA; ${ }^{2}$ Department of \\ Plant Biology, Southern Illinois University, Carbondale, Illinois 62901, USA; ${ }^{3}$ Department of Integrative Biology, \\ University of Guelph, 50 Stone Rd. East, Guelph, Ontario, Canada NIG 2W1
}

\begin{abstract}
Peatland ground layer species composition is intricately tied to ecosystem function (for example, carbon storage). As the primary disturbance in boreal bogs, wildfire selectively removes the ground layer vegetation, creating heterogeneous habitat conditions and initiating succession. However, the successional trajectory of the ground layer community following fire is poorly understood. Here we assess spatial and temporal changes in community composition along a chronosequence of post-fire bogs ( $1-105$ years since fire) in north central Alberta, Canada. We established vegetation plots in 13 bogs and repeatedly monitored them from 2003-2006. We found three phases of the post-fire bog community, grading from pioneer true moss (for example, Polytrichum strictum) dominance soon post-fire $(<10$ ysf) to persistent Sphagnum dominance in mature sites (20-80 ysf) with partial replacement by feathermosses (for example, Pleurozium schreberi) in older bogs (>80 ysf). Mature bogs dominated by Sphagnum fuscum
\end{abstract}

had the greatest species richness, although species evenness was low. Spatial heterogeneity of ground layer community composition was bimodal, peaking approximately 10 ysf (co-occurrence of true mosses and Sphagnum) and more than 80 ysf when feathermosses encroach and break-up Sphagnum dominance, resulting in inverse relationships of community species richness and diversity along the post-fire recovery gradient. Based on these results, we develop a conceptual model of post-fire bog recolonization and succession, in which microtopography, soil moisture, and combustion severity interact, thereby presenting the first comprehensive description of the spatio-temporal post-fire successional trajectory of the bog ground layer.

Key words: succession; peatland; fire; community; ecosystem; bog; trajectory analysis; intermediate disturbance hypothesis; non-metric multidimensional scaling.

2-3\% of the Earth's land surface (Gorham 1991). Disproportionate rates of production relative to decomposition allow peatlands to accumulate and store $\mathrm{C}$ as partially decomposed biomass (peat). The majority of $C$ fixation and soil organic matter input in peatlands is by bryophytes that dominate and almost completely cover the ground layer (Vitt 2000). Because production and decomposition rates vary among peatland bryophyte species (Turetsky 2003),
Received 15 October 2007; accepted 2 July 2008

Electronic supplementary material: The online version of this article (doi:10.1007/s10021-008-9178-4) contains supplementary material, which is available to authorized users.

*Corresponding author; e-mail: Benscot1@MSU.edu

Globally, peatlands account for nearly a third of the terrestrial carbon (C) pool while occupying only 
rates of peat accumulation are species-specific and subject to fluctuation with changes in ground layer composition (Aerts and others 1992; Camill and others 2001; Nordbakken 2001; Malmer and others 2005), making ground layer community composition important to the global C cycle.

Bogs are ombrotrophic peatlands, characterized by acidic, nutrient poor conditions that limit the number of species found therein. Sphagnum mosses dominate bogs due to their ability to tolerate and perpetuate the adverse conditions (Vitt 1990; Rydin 1993b), although species distributions vary along environmental gradients (Gignac and others 1991). Within bogs, the main environmental gradient affecting species distributions is microtopography and its concomitant range in water table proximity (Vitt 1990), establishing the range of possible microhabitats wherein a species may occur (fundamental niche). Trade-offs between desiccation avoidance (that is, water retention ability) and production rate result in restriction of the fundamental niche and partitioning of the microtopographic gradient (Titus and others 1983; Wagner and Titus 1984; Rydin and McDonald 1985; Rydin 1986, 1993a, b; Mulligan and Gignac 2001; Rydin and Barber 2001). Although all Sphagnum species are capable of surviving and have greater growth rates at lower microtopographic positions (Rydin 1993b) with the exception of extremely low, wet pools and hollows, the lower bounds of their realized niche is restricted by interspecific competitive interactions, favoring fast growing species of Section Cuspidata (for example, Sphagnum angustifolium) capable of overtopping their competitors (Titus and others 1983; Rydin 1986, 1993a). The upper bound of the realized niche is defined by the species' ability to avoid desiccation as distance from the water table increases (Wagner and Titus 1984; Rydin 1993b), favoring densely packed mats of Sphagnum fuscum (Section Acutifolia), which can maintain high soil moisture at great water table distances $(>50 \mathrm{~cm})$ despite the lack of vascular tissue through communal capillary retention of water. However, species with low water retention ability (for example, S. angustifolium, Polytrichum strictum, and so on) can exploit water retention by S. fuscum mats and occur as individuals outside their typical distribution range (Rydin 1993a, b).

In addition to Sphagnum, pioneer true mosses (for example, P. strictum, Aulacomnium palustre, and so on) and feathermosses (for example, Pleurozium schreberi, Hylocomnium splendens, and so on) occur in bogs. Pioneer true mosses are found in greatest abundance in disturbed areas (Maltby and others 1990; Groeneveld and Rochefort 2005; Benscoter
2006), whereas feathermosses (particularly $P$. schreberi) may be photo-inhibited (Palviainen and others 2005) and compete poorly with Sphagnum mosses at high water table positions (Mulligan and Gignac 2001), therefore restricting feathermosses to higher hummocks with greater shading by the Picea mariana canopy. Although the microtopographic distribution ranges of these species overlap those of Sphagnum species, temporal and concurrent environmental factors (that is, time since disturbance, degree of shading) limit co-occurrence.

The bog ground layer community changes temporally through succession, particularly in response to disturbance (Benscoter and others 2005b). In western Canada, fire is the predominant form of peatland disturbance (Turetsky and others 2002), consuming approximately $1850 \mathrm{~km}^{2}$ annually (Turetsky and others 2004). Burn severity is variable within bogs (Maltby and others 1990; Zoltai and others 1998; Turetsky and Wieder 2001), ranging from lightly burned or intact peat surfaces and vegetation on hummocks to several centimeters of peat consumption in low-lying hollows (Benscoter and Wieder 2003), although some hummocks or portions thereof experience severe consumption (Benscoter and others 2005b). Because hollows are the lowest possible microtopographic state in bogs and some hummocks are burned, the relative frequency of hollows is increased post-fire, changing microhabitat structure and availability (Benscoter and others 2005a, b). The resulting variability in ground layer vegetation removal and charcoal deposition creates a variety of post-fire revegetation starting points (Maltby and others 1990; Zoltai and others 1998; Benscoter and Wieder 2003), which may result in heterogeneous ground layer recovery (Benscoter 2006).

Although patterns of bog floral community composition have been described for mature bogs, temporal trends in both composition and spatial pattern are lacking. In this study, we examined the spatial and temporal change in bog ground layer community composition along a post-fire chronosequence to develop a compositional recovery trajectory for post-fire bogs of western Canada. In particular, we investigated two questions: (1) what communities are present on the post-fire bog landscape and (2) what are the patterns and mechanisms governing community change through post-fire succession?

A space-for-time chronosequence approach with repeated sampling in bogs allows for coupled assessment of spatial and temporal community change and alleviates problems of spatial scope of inference or confounding variables to which chro- 
nostratigraphic and long-time interval approaches are susceptible. Because bryophyte propagules are widely dispersed and readily available (Rydin and Barber 2001; Campbell and others 2003; RossDavis and Frego 2004), the possible bog species pool is spatially uniform. Therefore there is relatively little floral variability among bogs at the landscape level, alleviating compositional variability due to spatial processes alone. Furthermore, repeated sampling and overlap in post-fire recovery times allows for assessment of parsimony between space-for-time and in situ based inferences. As a result, this study presents the first comprehensive description of spatial and temporal compositional change of the continental bog ground layer in response to wildfire.

\section{MethoDS}

\section{Site Selection}

In 2003, a chronosequence of historically burned bogs in Alberta, Canada, was selected by visually overlaying maps of peatland distribution (Vitt and others 1996) and historical fire occurrence (Delisle and Hall 1987) to identify areas with a high incidence of bog as well as a history of fire. These candidate areas were then assessed using aerial photographs (Alberta Sustainable Resource Development, Edmonton, Alberta) to identify burned bogs, indicated by the presence of fire scars on the landscape, within reasonable proximity to road access. Because the historical fire records for $\mathrm{Al}$ berta only extend back to the 1930s (Delisle and Hall 1987), dendrochronological analysis of the serotinous Picea mariana found in the bogs was required to determine the approximate year of fire occurrence for more mature sites (D. H. Vitt, Unpublished data). Five peatland complexes were selected in 2003, each with two fire histories referred herein as burned (more recent fire) and unburned (older fire), and a single bog was identified within each fire history. An additional three bogs with a single fire history were added in 2004, resulting in a chronosequence of 13 bogs ranging 1-102 years since fire at the inception of the study (Table 1).

\section{Experimental Design and Analysis}

At each bog, a transect was established through the center of the burned area with five plots randomly placed along the length of the transect. Within each plot, five $0.5 \times 0.5-\mathrm{m}$ quadrats were placed at equal distances along a separate $5-\mathrm{m}$ transect. Composition of the ground and shrub layers were visually assessed by \% cover of the quadrat area and tree canopy cover was assessed using a concave spherical densiometer. All quadrats were repeatedly monitored for at least three years during the

Table 1. Site Location and Description of Sampling Scheme

\begin{tabular}{|c|c|c|c|c|c|c|}
\hline \multirow[t]{2}{*}{ Site } & \multirow[t]{2}{*}{ Location } & \multirow{2}{*}{$\begin{array}{l}\text { Time since } \\
\text { fire (years) }\end{array}$} & \multicolumn{4}{|c|}{ Sampling } \\
\hline & & & 2003 & 2004 & 2005 & 2006 \\
\hline \multicolumn{7}{|l|}{ Two fire histories } \\
\hline \multirow[t]{2}{*}{ Crow Lake } & $55^{\circ} 43.286 \mathrm{~N}$ & 1 & $\mathrm{~V}$ & $\mathrm{~V}$ & $\mathrm{~V}, \mathrm{CC}$ & V \\
\hline & $112^{\circ} 11.704 \mathrm{~W}$ & $102 *$ & $\mathrm{~V}$ & & $\mathrm{~V}, \mathrm{CC}$ & $\mathrm{V}$ \\
\hline \multirow[t]{2}{*}{ Pelican Lake } & $55^{\circ} 48.039 \mathrm{~N}$ & 4 & $\mathrm{~V}$ & $\mathrm{~V}$ & $\mathrm{~V}, \mathrm{CC}$ & $\mathrm{V}$ \\
\hline & $113^{\circ} 22.362 \mathrm{~W}$ & $90 *$ & $\mathrm{~V}$ & & $\mathrm{~V}, \mathrm{CC}$ & V \\
\hline \multirow[t]{2}{*}{ Red Earth Creek } & $56^{\circ} 22.408 \mathrm{~N}$ & 21 & $\mathrm{~V}$ & & $\mathrm{~V}, \mathrm{CC}$ & $\mathrm{V}$ \\
\hline & $115^{\circ} 17.099 \mathrm{~W}$ & 54 & $\mathrm{~V}$ & & $\mathrm{~V}, \mathrm{CC}$ & $\mathrm{V}$ \\
\hline \multirow[t]{2}{*}{ Utikuma Lake } & $55^{\circ} 59.245 \mathrm{~N}$ & 51 & $\mathrm{~V}$ & & $\mathrm{~V}, \mathrm{CC}$ & $\mathrm{V}$ \\
\hline & $115^{\circ} 11.081 \mathrm{~W}$ & $88^{*}$ & $\mathrm{~V}$ & & $\mathrm{~V}, \mathrm{CC}$ & $\mathrm{V}$ \\
\hline \multirow[t]{2}{*}{ Wabasca } & $55^{\circ} 54.549 \mathrm{~N}$ & 63 & $\mathrm{~V}$ & & $\mathrm{~V}, \mathrm{CC}$ & $\mathrm{V}$ \\
\hline & $113^{\circ} 36.652 \mathrm{~W}$ & $103 *$ & $\mathrm{~V}$ & & $\mathrm{~V}, \mathrm{CC}$ & $\mathrm{V}$ \\
\hline \multicolumn{7}{|l|}{ Single fire history } \\
\hline Mariana Lake & $\begin{array}{l}56^{\circ} 01.344 \mathrm{~N} \\
111^{\circ} 55.842 \mathrm{~W}\end{array}$ & 8 & & $\mathrm{~V}$ & $\mathrm{~V}, \mathrm{CC}$ & $\mathrm{V}$ \\
\hline Plamondon & $\begin{array}{l}54^{\circ} 56.531 \mathrm{~N} \\
112^{\circ} 19.499 \mathrm{~W}\end{array}$ & 39 & & $\mathrm{~V}$ & $\mathrm{~V}, \mathrm{CC}$ & $\mathrm{V}$ \\
\hline Utikuma Lake East & $\begin{array}{l}55^{\circ} 48.735 \mathrm{~N} \\
115^{\circ} 9.626 \mathrm{~W}\end{array}$ & $80 *$ & & $\mathrm{~V}$ & $\mathrm{~V}, \mathrm{CC}$ & $\mathrm{V}$ \\
\hline
\end{tabular}

Time since fire is elapsed time since most recent fire as of 2003. Ages marked with asterisk $(*)$ obtained through dendrochronological analysis of Picea mariana; all other ages based on Delisle and Hall (1987). $V=$ vegetation survey; $C C=$ tree canopy cover. 
4 years of the study (Table 1). For assessing overall community composition and successional trajectories across the chronosequence, the quadrat compositions were averaged at the site level for each year to provide a reliable estimate of site composition. However, the individual quadrat compositions were used when investigating fine-scale (within site) compositional heterogeneity and change.

Ordination and cluster analyses were utilized to identify communities and assess change over the chronosequence. Non-metric multidimensional scaling (NMDS) was used to ordinate the sites at each time point (2003-2006) based on mean species cover averaged by site and year of collection using the Bray-Curtis (B-C) dissimilarity index (Faith and others 1987) and 100 random starts in DECODA v3.1 (Minchin 1998). Because the ordination is constructed using the rank order of dissimilarities among sample units, NMDS can utilize nonEuclidean or semi-metric dissimilarity indices that are more appropriate for community data than those underlying other ordination techniques (for example, PCA, CA, DCA; Faith and others 1987). The B-C (Sørensen) index is a measure of the shared abundance of two sample units divided by the mean total abundance of the sample units (McCune and Grace 2002), thereby avoiding problems of ambiguous shared absences in community data that befall other indexes (Faith and others 1987). Dimensionality of the final ordination was determined using a scree plot of the minimum stress obtained versus the number of dimensions to identify the optimal reduction in stress with dimensionality. The axes of the resulting ordination were rescaled in half-change beta diversity units (gradient length required for $50 \%$ turnover in species composition) (McCune and Grace 2002) and rotated to the principal axis of variation.

Hierarchical, polythetic, agglomerative clustering was performed in PCORD v4 (McCune and Mefford 1999) using the flexible beta fusion strategy with $\beta$ of -0.25 and $\mathrm{B}-\mathrm{C}$ index to summarize the sites into groups based on their mean composition. Indicator species analysis was used to identify species or groups of species with high constancy and fidelity within the groups identified by the cluster analysis.

Analysis of similarity (ANOSIM) was used to make pair-wise comparisons among the three cluster groups to determine if they occupy different positions in the NMDS ordination (McCune and Grace 2002). Vector fitting was used to determine the degree of correlation of the plot positions in the ordination with variables describing the nature of the plot (time since fire, diversity, tree canopy cover, species richness) and relativized based on their degree of correlation with the ordination. Monte Carlo simulations with 10000 permutations were performed in DECODA to test the significance of the ANOSIM and vector fitting results.

Because the sites were repeatedly sampled, we were able to quantify the successional change and directionality thereof by developing a trajectory analysis. For this, the distances between successive sampling points (years) in the NMDS ordination space was computed for each site (that is, 2003$>2004,2004->2005,2005->2006)$, as was the distance between the initial and final sampling (2003->2006), providing the total (summed path of change) and absolute (displacement from starting composition) amounts of change, respectively. By using the distances in ordination space, the distances among sample points were constrained by the total "landscape" (all points in the ordination), thereby minimizing "noise" from small variations in abundance (for example, $\pm 5 \%$ cover) and relativizing the magnitude of change across the entire dataset. The sites were then partitioned by developmental stage (young, 1-11 ysf; mature, 21-66 ysf; and old, $\geq 80 \mathrm{ysf}$ ) and the mean total and absolute change for each developmental stage were compared using ANOVA.

The directionality of change (that is, does all change result in deviation from the starting point or does the community "circle back") was assessed by dividing the absolute change by the total change, expressing displacement as a proportion of the total change. Although this proportion will assess the directionality of succession, it does not account for differences in magnitude of the change among sites. Two sites may have the same proportion of absolute:total change (for example, shape of triangles) but differ in their magnitude (for example, size of triangles). To account for differences in magnitude, the absolute:total change ratio was multiplied by the absolute change. The resulting values of the index were plotted as a function of fire recovery time (years) at first sampling. Also, the mean index values for the three developmental stages were compared using ANOVA.

Patterns of dominance across the chronosequence of Sphagnum mosses, feathermoss, true mosses, vascular shrubs, and bare/burned peat were assessed by plotting the summed abundances of species within each of the five categories against time since fire. Curves were fitted to the Sphagnum moss, feathermoss, and bare/burned area abundance distributions using PROC NLIN in SAS (SAS Institute, Cary, NC, USA).

To assess within-bog spatial variability of ground layer composition along the chronosequence, the 
mean B-C dissimilarity of quadrats within sites for each sampling year was calculated using species abundance data and plotted against time since fire. Sample points were then grouped into the aforementioned three developmental stages (young, mature, and old) and the mean multivariate dispersion of plots from the centroid (compositional heterogeneity) was calculated for each group based on the B-C index and compared using a multivariate extension of Levene's test (Anderson and others 2006) in PERMDISP2 (Anderson 2006).

To determine whether species abundance or presence-absence was responsible for observed patterns of temporal and spatial change, plot composition in 2003 was compared to 2006 using B-C dissimilarity on abundance ( $\%$ cover) and presence-absence data. The plot dissimilarity between time points was averaged by bog for each metric and plotted against time-since fire at the final sampling (2006). Only the original 10 bogs were used, as 2003 data were unavailable for the remaining three sites.

A similar approach was used to examine the cause of fine-scale community change in early post-fire (young) sites. The interannual B-C dissimilarities among quadrats were calculated using abundance (\% cover) and presence-absence data. The dissimilarities were averaged for successive time points (for example, 1-2 ysf, 2-3 ysf, and so on) and regressed against time since fire for both metrics.

\section{RESUlts}

Separation of the sites into three groups based on community composition accounted for greater than $50 \%$ of the information in the cluster analysis dendrogram (see Supplementary Material). These communities are characterized by (1) feathermosses, (2) S. fuscum and shrubs, and (3) charred peat and true mosses ( $P$. strictum). The major axis of change in the ordination corresponds with progressive ground layer reestablishment (Figure 1), moving from charred peat dominance soon postfire to $S$. fuscum dominance at longer recovery intervals. If the cluster dendrogram is extended to four groups, the Mariana Bog site (9-11 ysf) forms the fourth group exclusively, suggesting this site has a ground layer community transitional between an early successional pioneer true moss community and a S. fuscum dominated mature bog community. The canopy cover vector explains much of the variation along the second ordination axis, partitioning the feathermoss and S. fuscum dominated communities.

Based on the trajectory analysis, absolute compositional change was proportional to the summed interannual changes (total change) $\left(r^{2}=0.90\right.$; $\left.F_{1,11}=107.5, P<0.001\right)$, resulting in a consistent absolute:total change ratio of $0.7 \pm 0.2$ across the sites. Although the proportions were constant, young sites had greater magnitudes of absolute $\left(F_{2,10}=12.38, \quad P=0.002\right)$ and total change

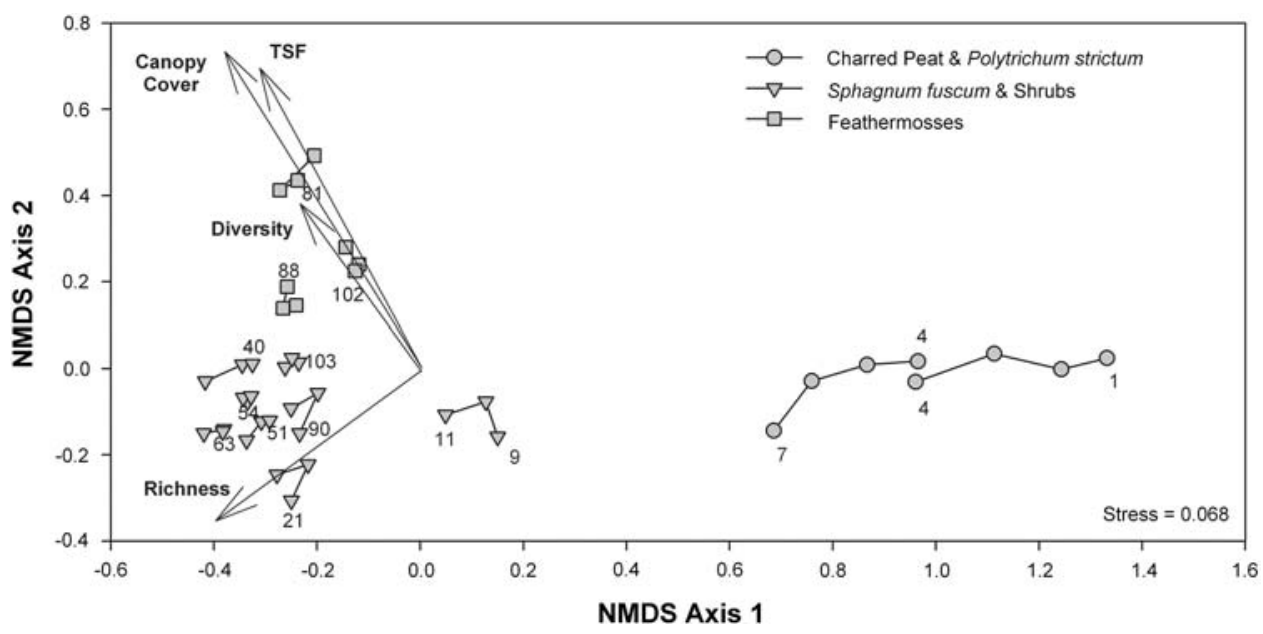

Figure 1. Two-dimensional NMDS ordination of plot vegetation survey data for 13 sites sampled quasi-annually from 2003-2006 (see Table 1). Significant vectors $(P<0.05)$ of time since fire $(r=0.82)$, reciprocal of Simpson's diversity index $(r=0.46)$, species richness $(r=0.53)$, and tree canopy cover $(r=0.77)$ scaled relative to their correlation coefficient. Labeling corresponds to cluster analysis groupings (Supplemental Material) and indicator species analysis results. Points representing successive annual assessments at a site are connected and annotated with time since fire (years) at first sampling (final sampling TSF labeled for early post-fire sites). Groups within ordination are significantly different based on $\operatorname{ANOSIM}(R=0.86, P<0.001)$. 


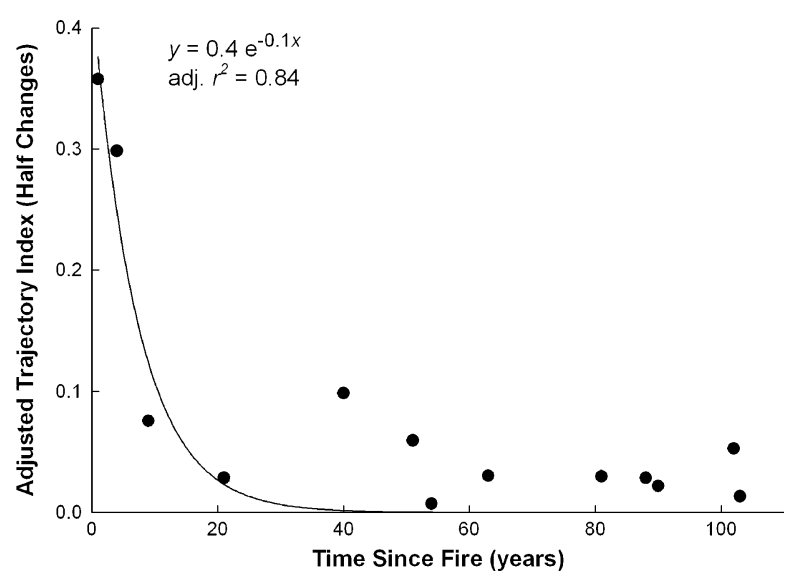

Figure 2. Adjusted trajectory index, a weighted measure of successional community change, by site along the post-fire chronosequence. Points represent ratio of absolute:total distance in NMDS multiplied by the absolute distance to scale for the magnitude of change. X-axis is post-fire recovery time in 2003.

$\left(F_{2,10}=10.84, P=0.003\right)$ than later developmental stages, resulting in a negative exponential trend in the adjusted trajectory index over the chronosequence (Figure 2). Due to rapid ground layer recolonization and the shift from a true moss to $S$. fuscum dominated community resulting in rapid and extreme inflection of the successional trajectory, the exponential model underestimates finescale community change at mid- and late-successional stages.

Substantial shifts in species group dominance were observed across the chronosequence (Figure 3).

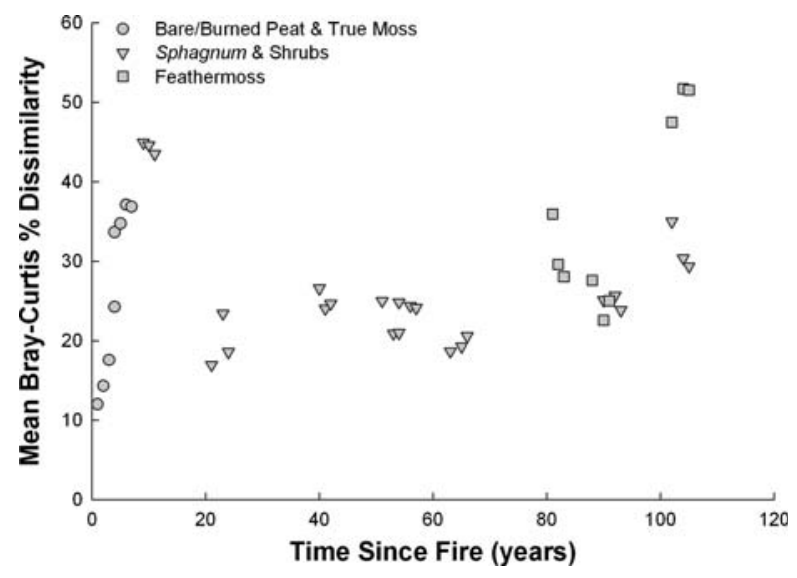

Figure 4. Mean within-site \% dissimilarity (spatial heterogeneity) among quadrats within each bog. Labeling corresponds to cluster analysis groupings and indicator species analysis results.

Bare/burned area showed a sharp decline over time with a concurrent increase in moss and vascular species abundance. True moss abundance plateaus and declines between 10 and 20 ysf, whereas Sphagnum and vascular species abundances continued to increase. After 80 ysf, feathermosses become more abundant and in some cases dominant.

Significant amounts of within-site change were found along the chronosequence, corresponding with changes in community type (Figure 4). Comparison of the developmental stage groups showed a significant difference in mean within-site compositional dissimilarity $\left(F_{2,1021}=82.4, P=0.009\right)$, with

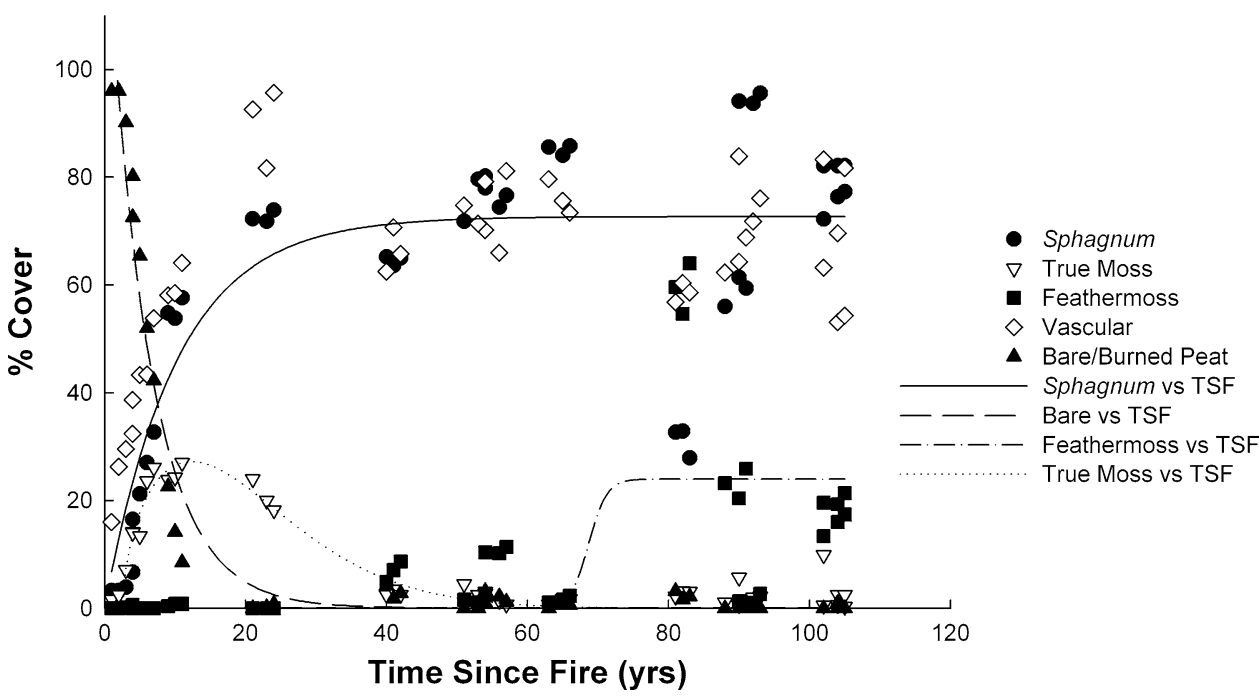

Figure 3. Change in dominance of species groups over time. Dominance is the summed cover of all species for that group at each time point by site. Bryophytes and vascular plants assessed separately, so summed cover values for all species may be greater than $100 \%$. Fitted curves: Sphagnum $\left(F_{1,39}=8.46, P<0.001 ; r^{2}=0.68\right), y=72.7\left(1-\mathrm{e}^{-0.1 \mathrm{x}}\right)$; bare/burned peat $\left(F_{1,39}=1383, P<0.001 ; r^{2}=0.97\right), y=1.3\left(\mathrm{e}^{-0.2 \mathrm{x}}\right)$; feathermoss $\left(F_{2,38}=13.17, P<0.001 ; r^{2}=0.38\right), y=\frac{24}{1+e^{-\left(\frac{x-69}{1.3}\right)}}$. 
early post-fire sites having significantly more spatial heterogeneity in ground layer composition than mature or old bogs.

Variability in plot dissimilarity between 2003 and 2006 was greater based on species presence-absence (Figure 5B) than abundance (Figure 5A) across the chronosequence, with the exception of the most recently burned sites. The incorporation of species abundance appears to have a dampening effect on the degree and variance of plot dissimilarities, particularly for intermediate aged (mature) sites.

The effects of species richness and abundance on community change in early post-fire sites (1-12 ysf) were inversely proportional (Figure 6). Mean dissimilarity based on abundance data showed a significant positive relationship with time since fire $\left(F_{1,5}=175.62, \quad P<0.001\right.$; Figure 6A). However, the presence-absence dissimilarities showed a
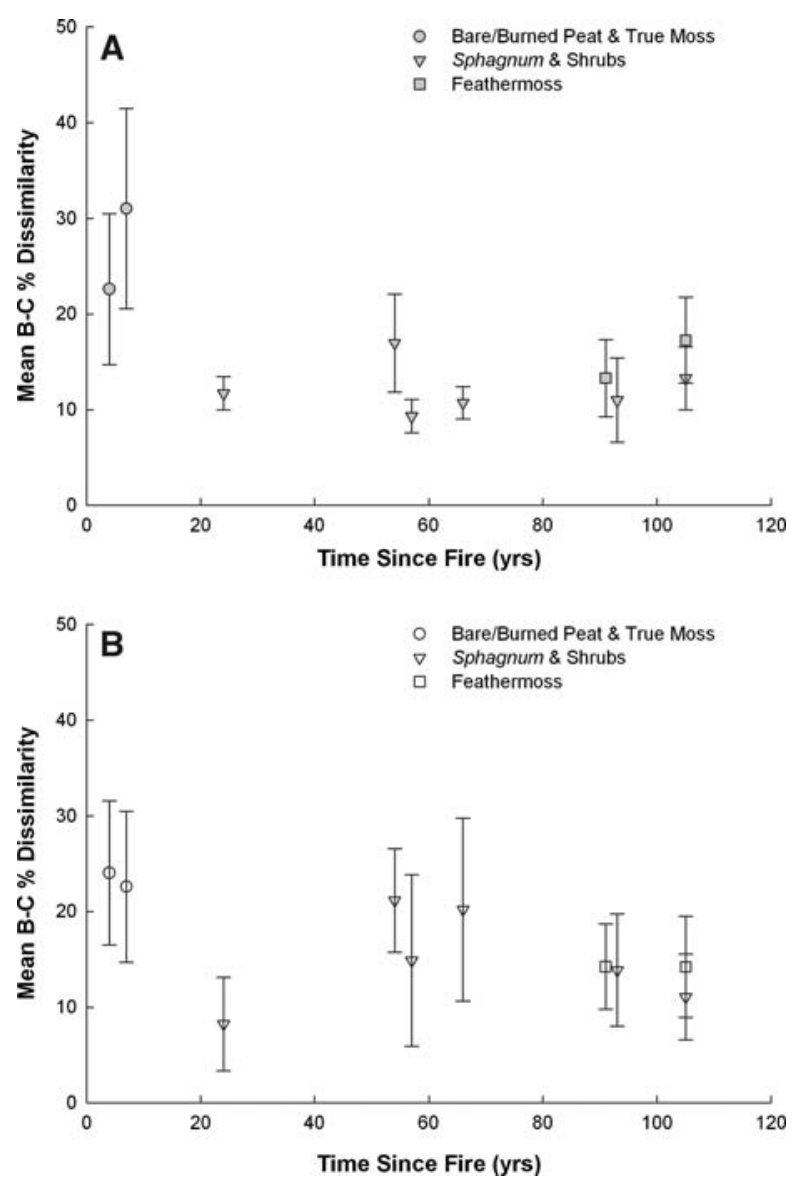

Figure 5. Mean compositional change $( \pm S D)$ from 2003 to 2006 of quadrats $(n=25)$ from 10 sites along post-fire chronosequence calculated using (A) \% cover (closed symbols) and (B) presence-absence data (open symbols). Labels correspond to results of cluster and indicator species analyses.
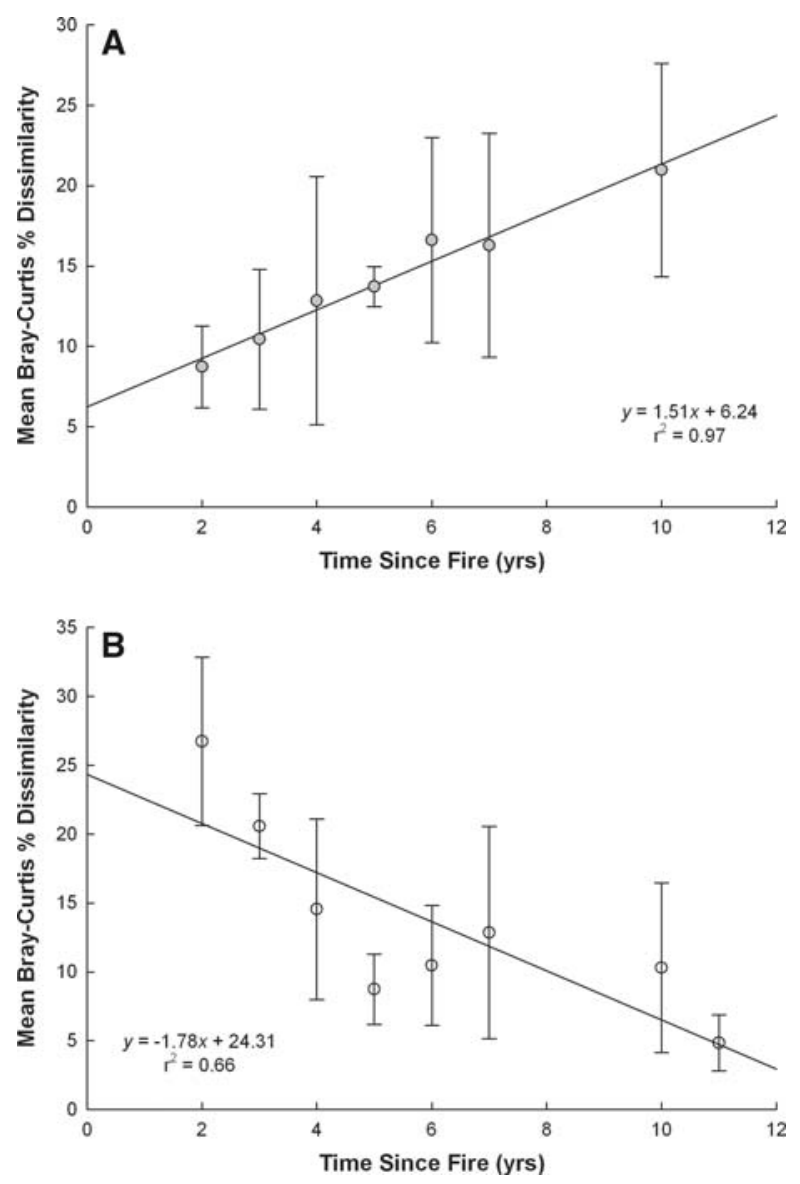

Figure 6. Mean interannual compositional change $( \pm \mathrm{SD})$ of repeatedly assessed quadrats $(n=25)$ within early post-fire sites (1-1 l ysf) and time since fire at final sampling using (A) \% cover (closed symbols) and (B) presence-absence data (open symbols).

negative trend $\left(F_{1,6}=11.88, \quad P=0.0137 ; \quad\right.$ Figure $6 \mathrm{~B})$.

\section{Discussion}

Post-fire succession of the bog ground layer community can be split into three phases. True mosses dominate the early post-fire community, although in low abundance, with shifts to Sphagnum and feathermoss dominance over time. These phases result from trade-offs among life history strategies and positive (facilitation) and negative (competition) interspecific interactions, and coincide with changes in the peat surface environment. The greatest degree of community change occurs in the first 10 years post-fire as the ground layer is recolonized, with a rapid decline in relative successional change as $S$. fuscum abundance increases. Once $S$. fuscum assumes dominance, the community remains relatively stabile with minor fine-scale 
change due to small shifts in relative species abundance, the appearance and disappearance of rare species, and, at later successional stages, the encroachment of feathermosses.

The high spatial heterogeneity of ground layer composition observed within early post-fire bogs is most likely due to heterogeneous combustion of the ground layer (Benscoter and Wieder 2003), which, along with possible abiotic changes (for example, soil moisture, nutrient availability) and removal of competition, creates a wide range of post-fire microhabitats. True mosses dominate the early post-fire phase because of their ability to colonize bare peat or heavily deposited charcoal and because competition by larger, faster growing Sphagnum species has been removed. Maltby and others (1990) and Benscoter (2006) also found true mosses, particularly Polytrichum spp., to be early post-fire colonizers in peatlands.

As the bog surface recovers from fire, Sphagnum species become more abundant, completely covering previously bare areas and replacing pioneer true mosses. Sphagnum fuscum can recover without facilitation on intact, lightly burned hummocks by resprouting from stems of previous individuals (Clymo and Duckett 1986), although this lags behind colonization of lower, wetter areas by true mosses (Benscoter 2006), possibly due to physiological requirements for resprouting. Resprouting of S. fuscum on hummocks was observed in this study, but not explicitly documented, approximately 3-4 years post-fire.

Over time, S. fuscum assumes dominance, forming a relatively stabile and spatially homogenous community that persists from approximately 2580 years post-fire. As time progresses, canopy shading and microtopographic elevation become great enough to allow P. schreberi and other feathermosses to establish on the higher hummocks, increasing spatial heterogeneity and evenness within the bog. Gunnarsson and others (2002) also found increased occurrence of $P$. schreberi with increased tree canopy formation.

Although moss community change is driven by facilitative or competitive interactions, lichens (for example, Cladina spp., Cladonia spp.) do not occupy a specific microtopographic range or temporal stage. Instead, lichen occurrence and abundance appears to be opportunistic, either taking advantage of bare peat too dry for other species to occupy in early successional stages or by establishing at intermediate microtopographic positions. In these cases, the water table may have dropped, creating conditions too dry for $S$. angustifolium or S. magellanicum, allowing lichens to establish before the slower spreading S. fuscum populations can encroach. However, this lichen opportunism may be short lived, as encroachment of neighboring populations at the edges of lichen mats was commonly observed, although further study will be required to examine the nature of lichen/moss interactions in these systems.

Species richness shows a unimodal pattern over the chronosequence, with the greatest number of species present in the $S$. fuscum dominated community. Although S. fuscum dominates the ground layer in this community, there is a high incidence of rare species within the $S$. fuscum mat, particularly lichens, liverworts, and true mosses, resulting in greater species richness in these communities compared to earlier or later stages. This humpshaped distribution of diversity as a function of time since disturbance matches the predictions of the intermediate disturbance hypothesis (Connell 1978), in which community diversity increases over time as new microhabitats are created. Community complexity increases until the strength of interspecific competition increases and competitive exclusion occurs, lowering diversity at longer time points. However, when diversity of the bog ground layer is expressed as spatial compositional heterogeneity and incorporates the abundance and evenness of the community constituents, the pattern of diversity of the bog community with time since fire is inverted, with the S. fuscum community having much lower spatial heterogeneity (that is, spatial diversity) than earlier or later stages. This pattern is opposite that of the intermediate disturbance hypothesis, with greater diversity occurring during the competition free period initially following disturbance and at longer post-fire periods due to facilitation and encroachment of feathermosses.

The influence of species composition and abundance on community change shifts following fire. Early post-fire sites show large effects of composition as the ground layer is recolonized, with abundance becoming more influential as the limited species pool is filled. In mature surfaces of bogs recovering from fire (approximately 20-90 ysf), sporadic occurrence of rare species causes community variation, but the effect is minimized by the overwhelming dominance of $S$. fuscum, resulting in homogenous and persistent community structure both spatially and temporally. However, when the once rare species increase in abundance, as in the case of feathermosses in older peatlands, the impact of composition is increased.

Nordbakken (2001) found high degrees of finescale compositional change over a 5-year period in 
a Norwegian bog, with Sphagnum dominated hummocks becoming mud-bottoms or bare peat. We found comparable degrees of short-term compositional change in early post-fire sites, but not in older bogs, where fine-scale changes were tempered by persistent dominance of $S$. fuscum and, to a lesser extent, $P$. schreberi, which stabilized overall trends in spatial and temporal change in mature bogs. Furthermore, the successional direction of change was opposite. In the absence of disturbance, continental western Canadian bogs do not exhibit the same retrogressive, closed succession cycle observed in hummocks of oceanic Scandinavian bogs, wherein autogenic processes result in the replacement of Sphagnum and degradation of hummocks.

\section{SyNTHesis AND ConClusions}

Combining the results of this study with previous results (Benscoter and others 2005a, b; Benscoter
2006) and observations, we propose a conceptual model of continental bog ground layer response to fire (Figure 7). During a fire, combustion is variable, leaving portions of the bog completely unburned, whereas combustion severity in other areas ranges from light burning of surface vegetation to extensive combustion of the underlying peat (Zoltai and others 1998; Benscoter and Wieder 2003). For the purpose of this model, the scenario of complete fire avoidance (for example, unburned patches) was excluded, as their vegetation dynamics are not affected by the occurrence of fire.

Depending on pre-fire microtopographic position (hummock versus hollow) and combustion severity (light versus heavy), there are four scenarios of initial $(1 \sim 10 \mathrm{ysf})$ ground layer recovery post-fire (Figure 7). In Scenario A, a pre-fire hollow, typically $S$. angustifolium dominated, undergoes light combustion that, in conjunction with low microtopographic position and therefore wet conditions,

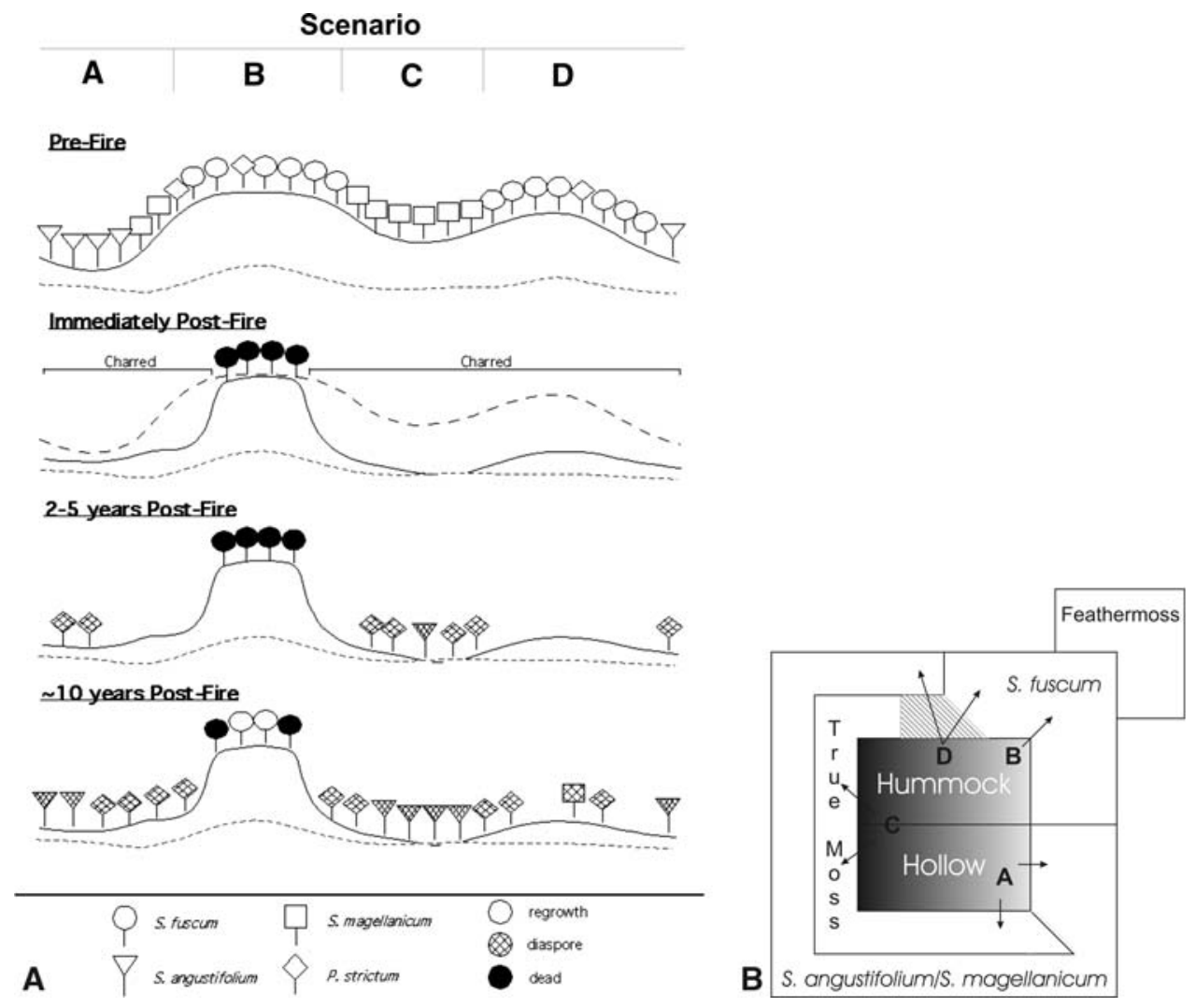

Figure 7. Conceptual models of post-fire bog ground layer succession trajectories depicting (A) initial ground layer recovery scenarios and $(\mathbf{B})$ placing these scenarios in the overall context of bog succession. In figure (A), letter labels indicate regeneration scenarios (described in Synthesis), solid line represents current peat surface, dashed line represents pre-fire peat surface, and dotted line represents water table position. In figure $(\mathbf{B})$, shading of inner square represents gradient of combustion severity from heavy (dark) to light (light gray), hatched area represents lag in re-vegetation, and letter labels and arrows correspond to recovery scenarios. Labeled outer boxes represent dominance of the indicated species/group. Succession proceeds by passing between adjacent boxes, with the overall direction of succession progressing to the upper right corner. 
allows for quick reestablishment from dispersed diaspores. Similarly, a hollow undergoing moderate to severe combustion would still be relatively wet, producing conditions favorable for colonization, although greater charcoal deposition may delay reestablishment. In either case, $P$. strictum and other pioneer true moss species colonize quickly post-fire and modify the microhabitat, facilitating S. angustifolium to return and eventually dominate the hollows.

Scenario B involves light combustion of portions of a pre-fire hummock. Although the margins of the hummock are more severely burned, the interior portions remain intact post-fire with only minor singeing of the tips (capitula) of $S$. fuscum plants. New S. fuscum plants eventually regrow either from dispersed diaspores or, more likely, from the remaining stems of previous individuals. Facilitation by true mosses is not required, as conditions favoring S. fuscum before the fire are still present, although there is a lag in the recovery response of these lightly burned hummocks compared to hollows.

If combustion on hummocks is severe (for example, as on $S$. magellanicum hummocks or the edges of $S$. fuscum hummocks), removing not only the surface vegetation but also a considerable amount of underlying peat, hollow conditions are created (Scenario C), resulting in colonization by pioneer true mosses followed by $S$. angustifolium as in Scenario A. If combustion is less severe, preserving higher microtopographic position, hummock species (for example, S. fuscum, S. magellanicum) can recolonize (Scenario D). However, there will be a lag in recolonization, as the soil conditions are too dry for true mosses or hollow sphagna, but too degraded (for example, high charcoal deposition, lack of viable fragments for resprouting, and so on) for hummock sphagna. Most likely these intermediate microtopographic areas will be the last to be re-vegetated as the hollow species encroach from below and the hummock species from above, "squeezing out" the bare peat or lichen community in between.

Once conditions become favorable for Sphagnum mosses, they will outcompete the true mosses and assume dominance of the peat surface. Heterogeneous environmental conditions, particularly proximity to the water table, results in spatial partitioning of Sphagnum species based on niche preference. Greater peat accumulation by Sphagnum further separates the peat surface from the water table, eventually favoring S. fuscum in all but the lowest relative microtopographic positions. However, as the surface rises further, facilitated by greater peat accumulation by S. fuscum, and Picea mariana canopy cover increases, the highest hummocks become too dry and S. fuscum's competitive ability decreases, allowing feathermoss encroachment. As peat accumulation continues in surrounding areas, the feathermosses will spread and assume dominance until a disturbance (that is, fire) restructures the microtopographic gradient, creating wetter conditions and allowing Sphagnum mosses to return.

Although autogenic factors play a role in bog ground layer community composition and spatial heterogeneity, the post-fire successional trajectory is chiefly governed by edaphic (allogenic) change and the adaptations of species thereto. Therefore, if environmental conditions were to change due to altered fire regimes or global warming, boreal bog vegetation could be drastically affected. Furthermore, because peatland function is controlled by community composition, such vegetation changes could alter boreal peatland C cycling.

\section{ACKNOWLEDGMENTS}

We thank Tiffany Bone for aging the trees of our older sites, Meanook Biological Station (Univ. of Alberta) for use of their facilities, and Drs. Kelman Wieder, David Gibson, Loretta Battaglia, and Charles Ruffner, as well as the reviewers, for their comments. Funding was provided by the National Science Foundation (DEB-0212333), US Environmental Protection Agency STAR fellowship, and Society of Wetland Scientists student research grant.

\section{REFERENCES}

Aerts R, Wallen B, Malmer N. 1992. Growth-limiting nutrients in Sphagnum-dominated bogs subject to low and high atmospheric nitrogen supply. J Ecol 80:131-40.

Anderson MJ. 2006. PERMDISP2: a FORTRAN computer program for permutational analysis of multivariate dispersions using permutation tests. Department of Statistics, University of Auckland, Auckland, New Zealand.

Anderson MJ, Ellingsen KE, McArdle BH. 2006. Multivariate dispersion as a measure of beta diversity. Ecol Lett 9:683-93.

Benscoter BW. 2006. Post-fire bryophyte establishment in a continental bog. J Veg Sci 17:647-52.

Benscoter BW, Vitt DH, Wieder RK. 2005. Association of postfire peat accumulation and microtopography in boreal bogs. Can J For Res 35:2188-93.

Benscoter BW, Wieder RK. 2003. Variability in organic matter lost by combustion in a boreal bog during the 2001 Chisholm fire. Can J For Res 33:2509-13.

Benscoter BW, Wieder RK, Vitt DH. 2005. Linking microtopography with post-fire succession in bogs. J Veg Sci 16:453-60.

Camill P, Lynch JA, Clark JS, Adams JB, Jordan B. 2001. Changes in biomass, aboveground net primary production, 
and peat accumulation following permafrost thaw in the boreal peatlands of Manitoba, Canada. Ecosystems 4:461-78.

Campbell DR, Rochefort L, Lavoie C. 2003. Determining the immigration potential of plants colonizing disturbed environments: the case of milled peatlands in Quebec. J Appl Ecol 40:78-91.

Clymo RS, Duckett J. 1986. Regeneration of Sphagnum. New Phytol 102:589-614.

Connell JH. 1978. Diversity in tropical rain forests and coral reefs. Science 199:1302-10.

Delisle G, Hall R. 1987. Forest fire history maps of Alberta, 19311983. Canadian Forest Service, Northern Forestry Centre, Edmonton, Alberta, Canada.

Faith D, Minchin P, Belbin L. 1987. Compositional dissimilarity as a robust measure of ecological distance. Vegetatio 69:57-68.

Gignac LD, Vitt DH, Zoltai SC, Bayley SE. 1991. Bryophyte response surfaces along climatic, chemical, and physical gradients in peatlands of western Canada. Nova Hedwigia 53:27-71.

Gorham E. 1991. Northern peatlands: role in the carbon cycle and probable responses to climatic warming. Ecol Appl 1:182-95.

Groeneveld EVG, Rochefort L. 2005. Polytrichum strictum as a solution to frost heaving in disturbed ecosystems: a case study with milled peatlands. Restor Ecol 13:74-82.

Gunnarsson U, Malmer N, Rydin H. 2002. Dynamics or constancy in Sphagnum dominated mire ecosystems? A 40-year study. Ecography 25:685-704.

Malmer N, Johansson T, Olsrud M, Christensen TR. 2005. Vegetation, climatic changes and net carbon sequestration in a North-Scandinavian subarctic mire over 30 years. Glob Chang Biol 11:1895-909.

Maltby E, Legg CJ, Proctor MCF. 1990. The ecology of severe moorland fire on the North York moors: effects of the 1976 fires, and subsequent surface and vegetation development. J Ecol 78:490-518.

McCune B, Grace J. 2002. Analysis of ecological communities. MjM Software, Gleneden Beach, OR.

McCune B, Mefford M. 1999. PC-ORD: multivariate analysis of ecological data. MjM Software, Glenden Beach, Oregon, USA.

Minchin P. 1998. DECODA: Database for Ecological Community Data. Anutech Pty. Ltd., Canberra, Australia.

Mulligan RC, Gignac LD. 2001. Bryophyte community structure in a boreal poor fen: reciprocal transplants. Can J Bot 79:404-11.

Nordbakken J-F. 2001. Fine-scale five-year vegetation change in boreal bog vegetation. J Veg Sci 12:771-8.

Palviainen M, Finér L, Mannerkoski H, Piirainen S, Starr M. 2005. Responses of ground vegetation species to clear-cutting in a borealforest: aboveground biomass and nutrient contents during the first 7 years. Ecol Res 20:652-60.

Ross-Davis AL, Frego KA. 2004. Propagule sources of forest floor bryophytes: spatiotemporal compositional patterns. Bryologist 107:88-97.

Rydin H. 1986. Competition and niche separation in Sphagnum. Can J Bot 64:1817-24.

Rydin H. 1993. Interspecific competition between Sphagnum mosses on a raised bog. Oikos 66:413-23.

Rydin H. 1993. Mechanisms of interactions among Sphagnum species along water-level gradients. Adv Bryol 5:153-85.

Rydin H, Barber KE. 2001. Long-term and fine-scale coexistence of closely related species. Folia Geobot 36:53-61.

Rydin H, McDonald AJS. 1985. Tolerance of Sphagnum to water level. J Bryol 13:571-8.

Titus J, Wagner D, Stephens M. 1983. Contrasting water relations of photosynthesis for two Sphagnum mosses. Ecology 64:1109-15.

Turetsky M, Wieder K, Halsey L, Vitt D. 2002. Current disturbance and the diminishing peatland carbon sink. Geophys Res Lett 29:2121-4.

Turetsky MR. 2003. The role of bryophytes in carbon and nitrogen cycling. Bryologist 106:395-409.

Turetsky MR, Amiro BD, Bosch E, Bhatti JS. 2004. Historical burn area in western Canadian peatlands and its relationship to fire weather indices. Global Biogeochem Cycles 18:GB4014.

Turetsky MR, Wieder RK. 2001. A direct approach to quantifying organic matter lost as a result of peatland wildfire. Can J For Res 31:363-6.

Vitt DH. 1990. Growth and production dynamics of boreal mosses over climatic, chemical, and topographic gradients. Bot J Linn Soc 104:35-59.

Vitt DH. 2000. Peatlands: ecosystems dominated by bryophytes. In: Shaw A, Goffinet B, Eds. Bryophyte biology. Cambridge: Cambridge University Press.

Vitt DH, Halsey LA, Thormann MN, Martin T. 1996. Peatland inventory map of Alberta. Phase 1. Overview of peatland resources in the natural regions and subregions of Alberta. National Centres of Excellence-Sustainable Forest Management, University of Alberta, Edmonton.

Wagner D, Titus J. 1984. Comparative desiccation tolerance of two Sphagnum mosses. Oecologia 62:182-7.

Zoltai SC, Morrissey LA, Livingston GP, de Groot WJ. 1998. Effects of fires on carbon cycling in North American boreal peatlands. Environ Rev 6:13-24. 